\title{
Adiposity is the Crucial Enhancer of COVID-19
}

\author{
Hidekatsu Yanai
}

\section{To the Editor}

A very recent study showed that patients with overweight and obesity admitted in a medical ward for severe acute respiratory syndrome coronavirus 2 (SARS-CoV-2)-related pneumonia, despite their younger age, required more frequently assisted ventilation and access to intensive care units (ICUs) or semiICU than normal-weight patients [1]. However, it remains still unknown why obese patients with coronavirus disease 2019 (COVID-19) develop severe outcomes.

Potential risks for severe COVID-19 in obesity before SARS-CoV-2 infection and the mechanisms for adipositymediated exacerbation of COVID-19 were shown in Figure 1. Angiotensin-converting enzyme (ACE) 2 is the cellular entry receptor of SARS-CoV-2 [2]. Increased ACE2 expression in chronic obstructive pulmonary disease (COPD) patients who are overweight compared to those not-overweight was observed [3], indicating that SARS-CoV-2 is more likely to enter the human body in obese people as compared with non-obese people. ACE2 is also present in vascular endothelial cells, the epithelia of lung and small intestine, and its expression is increased in lung alveolar epithelial cells and adipose tissue due to obesity [4]. Given that angiotensin receptor blockers (ARBs) and an ACE inhibitor (ACEI) upregulated ACE2 expression in animal studies, the concern might arise regarding whether ARBs and ACEIs would increase the morbidity and mortality of COVID-19 [5]. However, no clinical data exist regarding the effects of ARBs and ACEIs on human tissue ACE2 expression or activity in vivo [5]. Further, a very recent large study has shown the protective effects of ACEIs/ARBs against mortality in COVID-19 [6], challenging the association between ACEIs/ARBs use and severe COVID-19. The S1 domain of SARS-CoV-2 spike glycoprotein potentially interacts with human dipeptidyl peptidase 4 (DPP4), a key immunoregulatory factor for hijacking and virulence [7]. Increased DPP4 expression was observed in vascular endothelial cells, adipose tissue and liver in obese people [8], which can also make it easy for SARS-CoV-2 to enter human tissues.

It has been proposed that the increase of secretion of interleukin- 6 and tumor necrosis factor-alpha by adipose tissue

Manuscript submitted June 4, 2020, accepted June 10, 2020

Published online August 1, 2020

Department of Diabetes, Endocrinology and Metabolism, National Center for Global Health and Medicine Kohnodai Hospital, 1-7-1 Kohnodai, Ichikawa, Chiba 272-8516, Japan. Email: dyanai@hospk.ncgm.go.jp

doi: https://doi.org/10.14740/cr1118 in obesity-induced insulin resistance, could underlie the associations of insulin resistance with endothelial dysfunction and coagulopathy [9]. Insulin resistance is associated with elevated concentrations of fibrinolytic inhibitor plasminogen activator inhibitor-1 (PAI-1), and increased expression and secretion of PAI-1 by hepatocyte and endothelial cell are induced by insulin, triglyceride-rich lipoproteins [9]. Von Willebrand factor (VWF) is elevated in insulin-resistant states, suggesting insulin-resistance induces endothelial dysfunction [9].

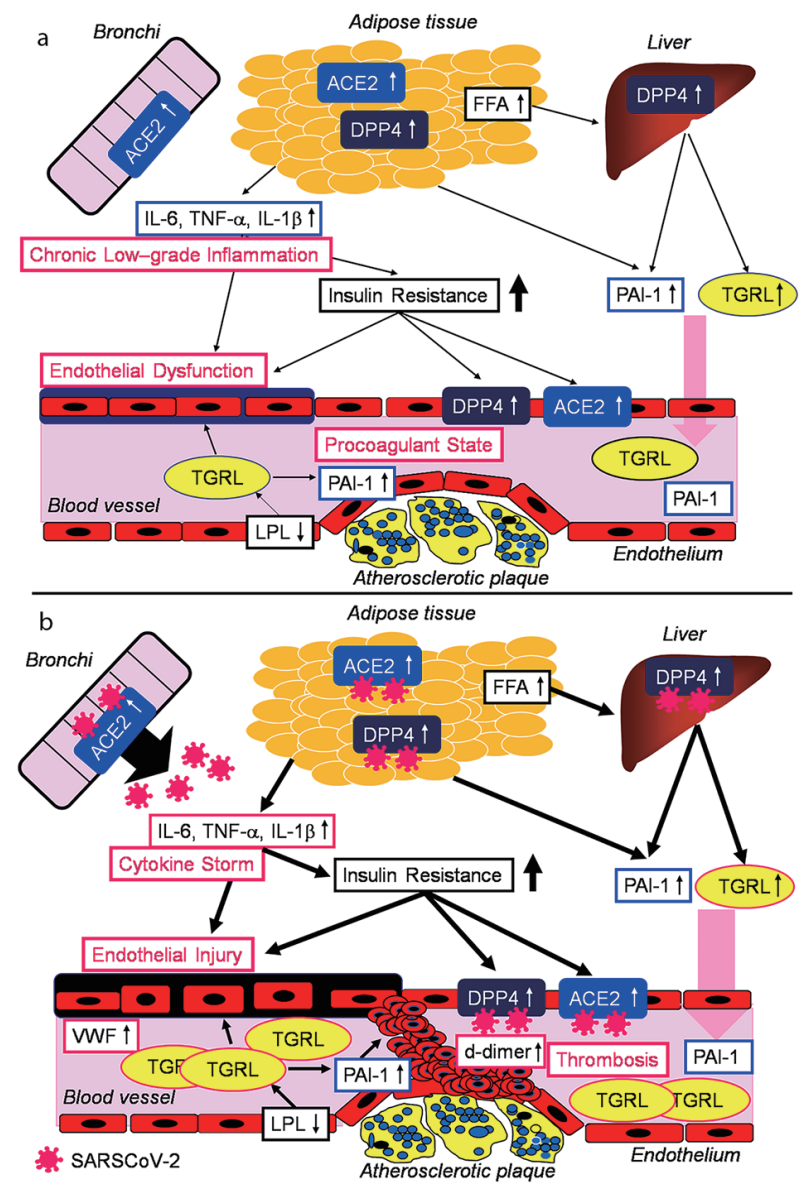

Figure 1. Potential risks for severe COVID-19 in obesity before SARSCoV-2 infection (a) and the mechanisms for adiposity-mediated exacerbation of COVID-19 (b). COVID-19: coronavirus disease 2019; SARS-CoV-2: severe acute respiratory syndrome coronavirus 2; ACE: angiotensin-converting enzyme; DPP4: dipeptidyl peptidase 4; FFA: free fatty acids; IL: interleukin; LPL: lipoprotein lipase; PAI-1: plasminogen activator inhibitor-1; TGRL: triglyceride-rich lipoprotein; TNF-a: tumor necrosis factor-alpha; VWF: von Willebrand factor. 
Elevation of inflammatory cytokines, endothelial dysfunction and procoagulant state already exist in obese people even before SARS-CoV-2 infection. SARS-CoV-2 infection may enhance elevation of inflammatory cytokines which leads to cytokine storm and induces endothelial injury. A highly inflammatory disorder may increase release of free fatty acids from adipose tissue and inactivate lipoprotein lipase [10], resulting in increase of triglyceride-rich lipoprotein which further enhance PAI-1 expression in vascular endothelium. Elevated PAI-1 and endothelial injury induce thrombosis. Multivariable regression showed remarkably increasing odds of in-hospital death associated with d-dimer (the marker for thrombosis) greater than 1 $\mu \mathrm{g} / \mathrm{mL}(18.42,2.64$ - 128.55; $\mathrm{P}=0.0033)$ on admission [11]. Elevated VWF (the marker for endothelial injury) level was also observed in COVID-19 patients in ICU [12]. Fibrinogen and ddimer also increased in patients in ICU, however, such patients did not develop acute disseminated intravascular coagulation (DIC), rather they showed hypercoagulability together with a severe inflammatory state [12], which I would call as "systemic severe coagulopathic vasculitis (SSCV)".I have to mention that the mechanical depression of ventilation due to morbid obesity may be associated with severity of COVID-19 [13].

In conclusion, obese people have various factors including high likelihood of entry of SARS-CoV-2 into human vital tissues, elevated cytokines, endothelial dysfunction and procoagulant state, which may enhance the severity of COVID-19.

\section{Acknowledgments}

I thank the staffs (Yukie Kawamura, Keiko Nakamura, Harue Aoki and Ayano Sakakibara) of the Division of Research Support, National Center for Global Health and Medicine Kohnodai Hospital.

\section{Financial Disclosure}

The author has no financial disclosures to report.

\section{Conflict of Interest}

The author declares that he has no conflict of interest concerning this article.

\section{Informed Consent}

Not applicable.

\section{Author Contributions}

H.Y. designed the research, collected and analyzed data. H.Y. wrote and approved the final paper.

\section{Data Availability}

The data supporting the findings of this study are available from the corresponding author upon reasonable request.

\section{References}

1. Busetto L, Bettini S, Fabris R, Serra R, Dal Pra C, Maffei P, Rossato M, et al. Obesity and COVID-19: an Italian snapshot. Obesity (Silver Spring). 2020.

2. Vaduganathan M, Vardeny O, Michel T, McMurray JJV, Pfeffer MA, Solomon SD. Renin-angiotensin-aldosterone system inhibitors in patients with COVID-19. N Engl J Med. 2020;382(17):1653-1659.

3. Higham A, Singh D. Increased ACE2 expression in the bronchial epithelium of COPD patients who are overweight. Obesity (Silver Spring). 2020.

4. Engin AB, Engin ED, Engin A. Two important controversial risk factors in SARS-CoV-2 infection: obesity and smoking. Environ Toxicol Pharmacol. 2020;78:103411.

5. Kai H, Kai M. Interactions of coronaviruses with ACE2, angiotensin II, and RAS inhibitors-lessons from available evidence and insights into COVID-19. Hypertens Res. 2020:1-7.

6. Zhang P, Zhu L, Cai J, Lei F, Qin JJ, Xie J, Liu YM, et al. Association of inpatient use of angiotensin-converting enzyme inhibitors and angiotensin II receptor blockers with mortality among patients with hypertension hospitalized with COVID-19. Circ Res. 2020;126(12):16711681.

7. Vankadari N, Wilce JA. Emerging WuHan (COVID-19) coronavirus: glycan shield and structure prediction of spike glycoprotein and its interaction with human CD26. Emerg Microbes Infect. 2020;9(1):601-604.

8. Nargis $T$, Chakrabarti P. Significance of circulatory DPP4 activity in metabolic diseases. IUBMB Life. 2018;70(2):112-119.

9. Yudkin JS. Abnormalities of coagulation and fibrinolysis in insulin resistance. Evidence for a common antecedent? Diabetes Care. 1999;22(Suppl 3):C25-30.

10. Bagby GJ, Spitzer JA. Lipoprotein lipase activity in rat heart and adipose tissue during endotoxic shock. Am J Physiol. 1980;238(3):H325-330.

11. Zhou F, Yu T, Du R, Fan G, Liu Y, Liu Z, Xiang J, et al. Clinical course and risk factors for mortality of adult inpatients with COVID-19 in Wuhan, China: a retrospective cohort study. Lancet. 2020;395(10229):1054-1062.

12. Panigada M, Bottino N, Tagliabue P, Grasselli G, Novembrino C, Chantarangkul V, Pesenti A, et al. Hypercoagulability of COVID-19 patients in intensive care unit. A report of thromboelastography findings and other parameters of hemostasis. J Thromb Haemost. 2020.

13. El-Solh A, Sikka P, Bozkanat E, Jaafar W, Davies J. Morbid obesity in the medical ICU. Chest. 2001;120(6):19891997. 